\title{
Genetic Diversity of Nepalese Indigenous Cattle Breeds Based on D-Loop Mitochondrial DNA
}

\author{
Neena Amatya Gorkhali ${ }^{1}$, Chhiring Sherpa ${ }^{1}$, Aashish Dhakal ${ }^{2}$, Sanjay Dhungana ${ }^{3}$, Saroj Sapkota ${ }^{1}$, \\ Prashanna Koirala $^{1}$, Bhoj Raj Pokhrel ${ }^{1}$, Manaraj Kolachhapati ${ }^{2}$, and Nirajan Bhattarai ${ }^{{ }^{*}}$ \\ ${ }^{I}$ National Animal Breeding and Genetics Research Centre, Nepal Agricultural Research Council, Lalitpur, Nepal. \\ ${ }^{2}$ Institute of Agriculture and Animal Science, Chitwan, Nepal \\ ${ }^{3}$ National Animal Breeding and Genetics Research Centre, Agriculture and Forestry University, Chitwan, Nepal.
}

\section{*CORRESPONDENCE: \\ Niranjan Bhattarai \\ National Animal Breeding and Genetics \\ Research Centre, Agriculture and Forestry \\ University, Chitwan, Nepal. \\ Email: nbhattarai@afu.edu.np}

ISSN : 2382-5359(Online), 1994-1412(Print)

DOI:

https://doi.org/10.3126/njst.v20i1.39435

ACCESS THE ARTICLE ONLINE

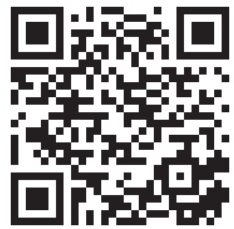

\section{CONFILICT OF INTEREST: None}

Copyright: The Author(s) 2020. This is an open access article under the CC BY license.

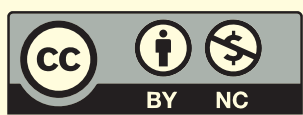

\begin{abstract}
Nepalese cattle are known for their genetic potentiality concerning inhabitant in extreme climatic conditions, surviving in the scarce food supply, and resistant to several diseases. We aimed to assess Nepal's ancestral origin and genetic diversity of indigenous cattle breeds based on hyper-variable D loop mtDNA sequences. Three cattle breeds (Siri, Achammi, \& Lulu) comprising the total sample population $(n=75)$ were employed in the study where the mt DNA information of two breeds (Achammi \& Lulu) were retrieved from the published source. Hyper-variable D loop (910bp) of Siri cattle was PCR amplified and sequenced. This study claims that the possible ancestral origin of Bos taurus and Bos indicus mtDNA lineage in the Nepalese cattle population is majorly influenced by China and India, respectively. This study suggests that Nepalese cattle can be divided into two major groups: Bos taurus and Bos indicus, where most of the cattle population was of Bos indicus origin. The sampled population can be classified into three significant haplogroups: T3 (25\%), I1 $(48 \%)$, and I2 (27\%) revealing a higher genetic diversity among the Nepalese cattle population. Only T3 taurine haplogroup was found in the sampled population. It was consistent with the fact that the absence of T1 haplogroup in North-East Asian cattle. In terms of Bos indicus, the I1 haplogroup was dominant over I2. Higher genetic diversity can be appropriate reasoning for Nepalese cattle's survival in a harsh environment and low food conditions.
\end{abstract}

Keywords: Ancestral, bos indicus, bos indicu, haplogroups

\section{INTRODUCTION}

Nepal is one of the countries with the highest livestock density per unit of cultivated land. Despite being a relatively small country, it is rich in animal genetic resources both in diversity and numbers. The contribution of livestock to gross domestic product (GDP) and agriculture gross domestic product (AGDP) in milk, meat, eggs, wool, manure, and draught power is 11 percent and 26.8 percent respectively. The documented cattle breeds of Nepal are Terai, Lulu, Pahadi, Siri, Khailia, Achhami, and Yak (Neopane \& Pokharel 2005). These native cattle are instrumental to the country's economy as it improves most Nepalese farmers' livelihood. Additionally, it provides indispensable milk and milk products to several 
farmers and consumers(Sharma et al. 2015). Nepalese indigenous breeds are more resistant to diseases, higher adaptation in harsh climatic conditions, and can reproduce even in a minimum supply of food (Gorkhali et al. 2020; Neopane \& Pokharel 2005)we collected $(\mathrm{n}=18$. Despite of the fact that here are limited researches on these subject matters. Only, a handful of molecular researches are found concerning Nepalese cattle breeds(Fujise et al. 2003; Gorkhali et al. 2020; Rana 1996; Takeda et al. 2004).

The study of mitochondrial DNA (mtDNA) has been an essential means to determine the maternal lineage, phylogeny, interspecies variability, evolutionary relationship between species, and population structure of various animals (Bhuiyan et al. 2007; Sun et al. 2020)in the southwest of China, is one of the putative migratory corridors or domestication centers for swamp buffalo. In this study, we investigated the evolutionary status of two Guangxi native buffalo breeds (Fuzhong buffalo, $n$ $=15$; Xilin buffalo, $\mathrm{n}=25$. Since the rate of nucleotide substitution is higher in mtDNA than nuclear DNA, it is an effective way to examine the hereditary varieties between closely related species (Brown, 1981; Brown et al. 1979) rhesus macaque, guenon, and human. Specifically, one of the control regions of mtDNA, D loop sequences, has been extensively exploited to study the evolution, origin, and diversification of modern domestic cattle (Jia et al. 2007)

The advanced cattle farming started from two domestication occasions of aurochs (Bos primigenius) in two distinct areas: Southwest Asia and South Asia. These two domestication processes offered to ascend to Bos taurus (taurine) in Southwest Asia whereas Bos indicus (zebuine) in South Asia(R. Loftus et al. 1999; Ronan Loftus et al. 1994; C. Troy et al. 2001)the most widely held view is that both types of cattle derive from a single domestication event 8000-10,000 years ago. We have examined mtDNA sequences from representatives of six European (taurine. The migration of humans for various purposes such as trade facilitated the spread of these domesticated animals to various parts of the world. The origin of taurine cattle occurred in the Near East region at around 8800 and $8300 \mathrm{BC}$ while domestication of zebu cattle started from Indus Valley during 6800 BC. A macro-haplogroup T was formed by converging all taurine cattle mtDNA sequences which possess six sub-haplogroup named T, T1, T2, T3, $\mathrm{T} 4$, and $\mathrm{T} 5$ which were scattered in Near East, Europe, Africa, and East Asia (Achilli et al. 2008; Mannen et al. 2004; C.Troy et al. 2001). Likewise, mtDNA sequences of the Bos indicus partitioned into two sub-haplogroups I1 and 12 (Chen et al. 2010).
Nepalese cattle are not researched adequately in finding the ancestral origin. Lulu's mtDNA information, the only native Bostaurus cattle, reveals some of it. D-loop mitochondrial sequences of Yak were found in Lulu, which resides at a higher altitude, whereas those found ata lower altitude embodied Bos indicus mtDNA(Fujise et al. 2003). In Achhami, most of the sampled population demonstrated Bos indicus haplotype, I1, and I2, while onlya few sampled populations shared Bos taurus haplotype(Gorkhali et al. 2020). The Bos taurus haplotype found in Achhami is quite different than that of Lulu (Hall 1999). The study has been carried out to assess the mtDNA diversity and possible origin of these three indigenous cattle breeds(Rana 1996; Takeda et al. 2004). To the best of the author's knowledge, no research has been undertaken to assess these three breeds' origin and mtDNA diversity. This research aids other investigators in knowing the ancestral origin and genetic diversity harbored by Nepalese indigenous breeds. The genetic diversity may be linked to positive attributes such as disease-resistant and adaptability; future research can be conducted following the significant output generated from this research (Gorkhali et al. 2021)

\section{MATERIALS AND METHODS}

\subsection{Sampling}

Blood samples from 22 Siri cattle were collected from Sindingba Rural Municipality of Taplejung district of Province-1 lying between $27^{\circ} 21^{\prime} 0$ " $\mathrm{N}$ and $87^{\circ} 40^{\prime} \mathrm{O} \mathrm{\prime}^{\prime \prime} \mathrm{E}$ (Table 2). Trained veterinary doctors followed ethical guidelines while withdrawing blood samples from animals. The individuals sharing unrelated parents and grandparents were selected as per the response collected from the respective owners. The collected blood samples were kept at -40 degrees Celsius until the DNA extraction process.

\subsection{DNA Extraction, PCR Followed by Sequencing}

PROMEGA DNA extraction kit was used for extracting DNA from blood samples followed by the company's protocol. The set of primer L15737: 5'-CTGCAGTCTCACCATCAACC-3' and H992: 5'-GCTGGGACCAAACCTATGTG-3' was used for amplifying D loop sequences of mtDNA (R. T. Loftus et al. 1994a)the most widely held view is that both types of cattle derive from a single domestication event 800010,000 years ago. We have examined mtDNA sequences from representatives of six European (taurine. The component of the $2 \mathrm{X}$ master mix is bacterially derived Taq DNA polymerase, $\mathrm{MgCl}_{2}, \mathrm{KCl}$, deoxynucleotides 
(dNTPs), Tris-HCL (pH-9), stabilizer and tracking dye. $25 \mathrm{ul}$ of PCR amplification reaction mixture was prepared by keeping $13 \mu$ l of PCR $2 X$ Master Mix, $5 \mu$ l of template DNA, $5 \mu \mathrm{l}$ of molecular grade nuclease-freewater, $1.5 \mu \mathrm{l}$ of forward, and $1.5 \mathrm{ul}$ of reverse primers. The PCR followed by sequencing was done. The optimum PCR condition: denaturation at $95^{\circ} \mathrm{C}$ for 1 minute, annealing at $58.0 \mathrm{C}$ for 1 minute, and extension at $72{ }^{\circ} \mathrm{C}$ for 2 minutes.

\subsection{Data Analysis}

The mtDNA sequences were manually edited and aligned by using Bioedit software (Hall 1999). The edited sequences were exported to MEGA 5 for creating a neighbor-joining phylogenetic tree (Tamura et al. 2011). The reference sequence of Bos taurus (accession number: V00654) of (Anderson et al. 1982) and Bos indicus (Accession no: L27733) of (R. T. Loftus et al. 1994)the most widely held view is that both types of cattle derive from a single domestication event 8000-10,000 years ago. We have examined mtDNA sequences from representatives of six European (taurine were used in the phylogenetic tree. The T1,T2,T3 Bos taurus haplotype and I1 and I2 Bos indicus haplotype of three cattle sampled population was also investigated by using reference sequences (Achilli et al. 2008; Hiendleder et al. 2008)which gave rise to taurine (Bos taurus. Haplotype and nucleotide diversity of each breed was calculated using DnaSP Version 3 (Rozas \& Rozas, 1999). Further, the NETWORK 4.1 program (http://www.Xuxus-engineering.com/sharenet.htm)was used to determine the median-joining network of the three cattle populations as a result of the case.

\section{RESULTS}

D loop mtDNA sequences (910 bp) of 75 indigenous Nepalese cattle were assessed. Among them, published mtDNA sequences of Lulu $(n=16)$ and Achammi $(n=37)$ were used (Fujise et al. 2003; Gorkhali et al. 2020; Takeda et al. 2004). The total number of Siri samples that were subjected for investigation was 22. The investigation found that 25\% shared Bos taurus and 75\% shared Bos indicus maternal lineage from the sampled population. The majority of the sampled population endowed Bos indicus mtDNA lineage. The native cattle, Siri, and Achammi embodied a higher proportion of zebu mtDNA, whereas Lulu claimed to be only Bos taurus cattle, have a higher proportion of taurine mitochondrial lineage (Table 1).

Table 1: Percentage of Bos taurus and Bos indicus clades in the sampled population

\begin{tabular}{|c|c|c|c|c|c|c|}
\hline \multirow{2}{*}{ Breeds } & \multicolumn{4}{|c|}{ Bos taurus clades } & \multicolumn{2}{c|}{ Bos indicus clades } \\
\cline { 2 - 7 } & T1 & T2 & T3 & T4 & I1 & I2 \\
\hline Achammi & 0 & 0 & $3(4 \%)$ & 0 & $22(29 \%)$ & $12(16 \%)$ \\
\hline Lulu & 0 & 0 & $12(16 \%)$ & 0 & $1(1 \%)$ & $3(4 \%)$ \\
\hline Siri & 0 & 0 & $4(5 \%)$ & 0 & $13(18 \%)$ & $5(7 \%)$ \\
\hline
\end{tabular}

The principal $\mathrm{T}$ haplogroup of Bos taurus is nominated into several haplogroups: T1, T2, T3, T4, and T5 (Mannen et al. 2004; C. Troy et al. 2001).T2, T3, and T4 haplogroup are distributed in North-East Asia, and the T1 haplogroup is in Africa (Mannen et al. 2004). Our observed result was consistent as the T3 haplogroup was dominant. No T1 haplogroup in three distinct indigenous breeds was found (Table 1). The overall percentage of Nepalese cattle clustered into T3 haplogroup was 16\% Lulu ( $n=12)$, $3 \%$ Achammi $(n-=3)$ and4\% Siri $(n=4)$. Similarly, indicus can be classified into I1 and I2. Nepalese cattle harboured I2 haplogroup ( $\mathrm{n}=20,27 \%)$ and I1 haplogroup ( 48\%). Mainly, Siri and Achammi samples showed I type haplogroup in greater proportion. More importantly, the I1 sub-haplogroup was dominant over I2 in the sampled population. A few Lulu samples also demonstrated I type haplo group despite possessing Bos taurus phenotypic characterization. The star-like network is disseminated in a median-joining network (Fig 1). The pattern suggests that population expansion might have happened in the past between two distinct clades.
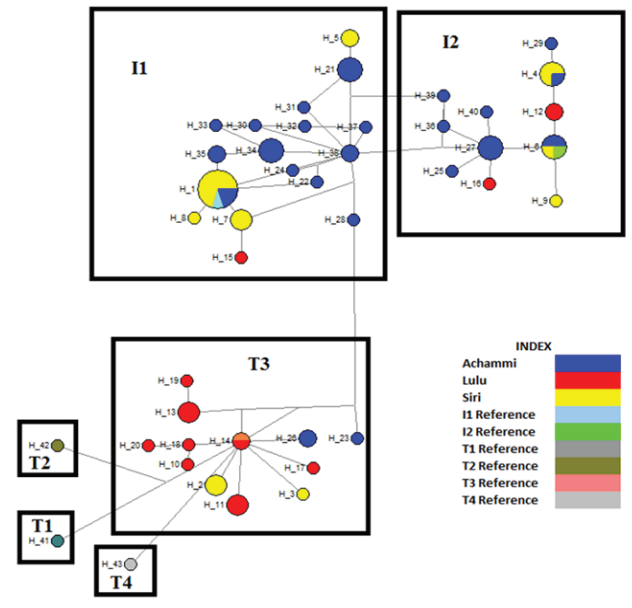

Fig. 1. NETWORK analysis showing major I1, I2, and T3 haplogroup shared by three distinct Nepalese cattle breeds.

The nucleotide and haplotype diversity of Nepalese cattle were studied. Varying nucleotide and haplotype diversity was found in Nepalese cattle breeds (Table 2). The number of haplotypes varied according to breed Achammi cattle shared higher haplotype diversity among three native Nepalese breeds. 
Table 2: Number of haplotypes, nucleotide diversity, and haplotype diversity of each Nepalese Indigenous breeds

\begin{tabular}{lccll}
\hline Breeds & $\begin{array}{l}\text { Num- } \\
\text { ber }\end{array}$ & $\begin{array}{c}\text { Number of } \\
\text { Haplo- } \\
\text { types }\end{array}$ & $\begin{array}{l}\text { Nucleotide Di- } \\
\text { versity }\end{array}$ & $\begin{array}{l}\text { Haplotype } \\
\text { Diversity }\end{array}$ \\
\hline Achammi & 37 & 29 & $0.01238 \pm 0.00295$ & $0.982 \pm 0.012$ \\
Lulu & 16 & 12 & $0.02250 \pm 0.00508$ & $0.958 \pm 0.036$ \\
Siri & 22 & 11 & $0.02118 \pm 0.00593$ & $\mathbf{i . 9 1 8 \pm} \pm$ \\
& & & & \\
\hline
\end{tabular}

\section{DISCUSSION}

Mannen et al. (2004) reported that cattle from Asian countries such as Korea and Japan do not share Bos indicus maternal lineage. However, we found more percentage of Bos indicus maternal lineages in Nepalese cattle despite being an Asian country. Concerning having two distinct clades (Bos indicus \& Bos taurus) in a median-joining network (Fig 1), it can be disseminated that the Nepalese cattle are distinct from the cattle found in Korea and Japan. Yu et al. (1999) claimed a majority of south China cattle have Bos indicus maternal lineage. It can be anticipated that these Chinese regions have closer proximity with India, where almost all cattle endow Bos indicus lineage (Loftus et al. 1994). Subsequently, breeding could have happened with zebu breeds. Consequently, it fosters critical reasoning about how more zebu maternal lines appeared in Chinese cattle breeds. Siri cattle are found in eastern Nepal whereas Achammi cattle are found in southwestern Nepal. Both areas have free access to the border with the neighboring country India. The free border assists Indian and Nepalese farmers in rear their animals across the border for breeding and trade purposes. As a result, a considerable percentage of zebu mtDNA may have appeared in these cattle.

It is reported that $\mathrm{T} 1$ haplogroup in African cattle, T2 haplogroup is found mainly in Mongolian cattle, T3 in Nepalese, Korean and Chinese cattle, and T4 in Japanese cattle (Lai et al. 2006; Mannen et al. 2004; C. S. Troy et al. 2001)we analyzed the complete mtDNA D-loop sequences of 84 cattle from 14 breeds/populations from southwest and west China, together with the available cattle sequences in GenBank. Our results showed that the Chinese cattle samples converged into two main groups, which correspond to the two species Bos taurus and Bos indicus. Although a dominant lineage was clearly discerned in both B. taurus and B. indicus mtDNAs, network analysis of the lineages in each of the two species further revealed multiple clades that presented regional difference. The B. taurus samples in China could be grouped into clades T2, T3, and T4, whereas B. indicus harbored two clades I1 and I2. Age estimation of these discerned clades showed a time range of 14,100-44,500 years before present (YBP. Previously, the T3 haplogroup was only reported in Nepal's Lulu cattle breed(Fujise et al. 2003; Takeda et al. 2004). Our study reveals that a few other Nepalese cattle breeds (Siri \& Achhami) having Bos indicus phenotypical characterization also shared T3 haplogroup. Chinese cattle have Bos taurus mtDNA lineage (Lai et al. 2006; Mannen et al. 2004)we analyzed the complete mtDNA D-loop sequences of 84 cattle from 14 breeds/populations from southwest and west China, together with the available cattle sequences in GenBank. Our results showed that the Chinese cattle samples converged into two main groups, which correspond to the two species Bos taurus and Bos indicus. Although a dominant lineage was clearly discerned in both B. taurus and B. indicus mtDNAs, network analysis of the lineages in each of the two species further revealed multiple clades that presented regional difference. The B. taurus samples in China could be grouped into clades T2, T3, and T4, whereas B. indicus harbored two clades I1 and I2. Age estimation of these discerned clades showed a time range of 14,100-44,500 years before present (YBP. The availability of Bos indicus maternal lineage in Chinese cattle is influenced by Southern China, where most cattle are near the Indian region (Yu et al. 1999). Achammi and Siri cattle share closer proximity with India. As a result, the majority of Bos indicus maternal lineage may have found in them. Lulucattle inhabiting in higher altitudes and closer to China, have a higher proportion of $\mathrm{T}$ haplogroup, especially T3 haplogroup. As the T3 haplogroup is found in China (Lai et al. 2006)we analyzed the complete mtDNA D-loop sequences of 84 cattle from 14 breeds/populations from southwest and west China, together with the available cattle sequences in GenBank. Our results showed that the Chinese cattle samples converged into two main groups, which correspond to the two species Bos taurus and Bos indicus. Although a dominant lineage was clearly discerned in both B. taurus and B. indicus mtDNAs, network analysis of the lineages in each of the two species further revealed multiple clades that presented regional difference. The B. taurus samples in China could be grouped into clades T2, T3, and T4, whereas B. indicus harbored two clades I1 and I2. Age estimation of these discerned clades showed a time range of 14,100-44,500 years before present (YBP, it can be expected that China might have influenced the T3 haplogroup in Lulu. The NETWORK analysis revealed that some Siri and Achammi populations also share Bos taurus mtDNA sequences (Fig 1). Besides some Lulu population sharbor Bos indicus mtDNA lineage despite being humpless taurine breeds. Fujise et al. (2003) and Takeda et al. (2004) claimed that Lulu found in lower 
altitudes shared Bos indicus mitochondrial sequences. It can be explained that these cattle may have undergone breeding with Achammi, Siri, or other Bos indicus breeds in past days. Random breeding may have occurred among these breeds. Overall, it can be disseminated that zebu and taurine mtDNA's possible ancestral origin is from India and China, respectively.

\section{CONCLUSION}

There exists a higher genetic diversity in Nepalese cattle samples despite inhabiting a small area. All three breeds demonstrated higher haplotype diversity. It infers that these cattle are unique from each other. The higher genetic diversity may have fostered Nepalese cattle to survive in extreme climates and be resistant to numerous diseases. Nepalese cattle breeds can be mainly divided into two distinct groups: Bos taurus and Bos indicus. Only T3 taurine haplogroup was found in the sampled population. It was consistent with the fact that the absence of T1 haplogroup in North-East Asian cattle. In terms of Bos indicus, the I1 haplogroup was dominant over I2. Even in a small area, higher genetic diversity in the sampled cattle population was found. Higher genetic diversity can be appropriate reasoning for Nepalese cattle's survival in a harsh environment and low food conditions. The mitochondrial analysis suggests that the origin of Nepalese Bos indicus and Bos Taurus might be from India and China, respectively.

\section{ACKNOWLEDGEMENT}

The authors express sincere gratitude to AFACI -Korea for providing the fund for the research and convey heartfelt thanks to staff of National Animal Breeding and Genetics Research Centre, NARC, for helping in sample collection.

\section{REFERENCES}

1. Achilli, A., A. Olivieri, M. Pellecchia, C. Uboldi, L. Colli, N. Al-Zahery, M. Accetturo, M. Pala, B.H. Kashani, U.A. Perego, V. Battaglia, S. Fornarino, J. Kalamati, M. Houshmand, R. Negrini, O. Semino, M. Richards, V. Macaulay, L. Ferretti, A. Torroni, 2008. Mitochondrial genomes of extinct aurochs survive in domestic cattle. Current Biology, 18(4), 157-158. https://doi.org/10.1016/j.cub.2008.01.019

2. Anderson, S., M.H. de Bruijn, A.R. Coulson, I.C. Eperon, F. Sanger \& I.G. Young. 1982. A complete sequence of bovine mitochondrial DNA. Conserved features of the mammalian mitochondrial genome. Journal of Molecular Biology, 156(4), 683-717. https://doi.org/10.1016/0022-2836(82)90137-1
3. Bhuiyan, M.S.A., A.K.F.H. Bhuiyan, D.H. Yoon, J.T. Jeon, C.S. Park \& J. H. Lee. 2007. Mitochondrial DNA diversity and origin of red Chittagong cattle. AsianAustralasian Journal of Animal Sciences, 20(10), 1478-1484. https://doi.org/10.5713/ajas.2007.1478

4. Brown, W.M. 1981. Mechanisms of Evolution in Animal Mitochondrial DNA. Ann N Y Acad Sci., 361, 119-134. https://doi.org/10.1111/j.1749-6632.1981. tb46515.x.

5. Brown, W.M., M. George \& A.C. Wilson. 1979. The rapid evolution of animal mitochondrial DNA. Proc. Natl. Acad. Sci. The USA, 76(4), 1967-1971. https:// doi.org/10.1111/1755-0998.12575

6. Chen, S., B.Z. Lin, M. Baig, B. Mitra, R.J. Lopes, A.M. Santos, D.A. Magee, M. Azevedo, P. Tarroso, S. Sasazaki, S. Ostrowski, O. Mahgoub, T.K. Chaudhuri, Y.P. Zhang, V. Costa, L.J. Royo, F. Goyache, G. Luikart, N. Boivin, ... A. Beja-Pereira. 2010. Zebu cattle are an exclusive legacy of the South Asia neolithic. Molecular Biology and Evolution, 27(1), 1-6. https:// doi.org/10.1093/molbev/msp213

7. Fujise, H., M. Murakami, B. Devkota, I.P. Dhakal, K. Takeda, H. Hanada, H. Fujitani, M. Sasaki \& K. Kobayashi. 2003. Breeding distribution and maternal genetic lineages in Lulu, a dwarf cattle population in Nepal. Animal Science Journal, 74(1), 1-5. https://doi. org/10.1046/j.1344-3941.2003.00078.x

8. Gorkhali, N.A., C. Sherpa, M.R. Kolachhapati, B.R. Pokharel, N. Bhattarai, \& S. Sapkota. 2021. Intermixing of Commercial Pure Breed Chickens with Indigenous (Sakini) Breed of Nepal. Journal of Nepal Agricultural Research Council, 7, 92-96. https://doi.org/10.3126/ jnarc.v7i1.36927

9. Gorkhali, N.A., C. Sherpa, N. Budhathoki, S. Gc, S. Lama, P. Pokharel, B.R. Pokhrel \& S. Sapkota. 2020. PCR Based Genotyping of Lulu Cattle of Nepal for A1, A2 Type Beta-caseins. Journal of Nepal Agricultural Research Council, 6, 56-61. https://doi.org/10.3126/ jnarc.v6i0.28115

10. Gorkhali, N., A. Dhakal, S. Sapkota, C. Sherpa, B. Pokhrel, M. Kolachhapati \& N. Bhattarai. 2020. Mitochondrial DNA polymorphisms in Nepalese Achhami cattle. Bangladesh Journal of Animal Science, 49(1), 22-28. https://doi.org/10.3329/bjas. v49i1.49374

11. Hall, T.A. 1999. BioEdit: A user-friendly biological sequence alignment editor and analysis program for Windows 95/98/N.T. (41:95-98.) [Computer software].

12. Hiendleder, S., H. Lewalski \& A. Janke. 2008. Complete mitochondrial genomes of Bos taurus and 
Bos indicus provide new insights into intra-species variation, taxonomy and domestication. Cytogenetic and Genome Research, 120(1-2), 150-156. https://doi. org/10.1159/000118756

13. Jia, S., H. Chen, G. Zhang, Z. Wang, C. Lei, R. Yao \& X. Han. 2007. Genetic Variation of Mitochondrial D-loop Region and Evolution Analysis in Some Chinese Cattle Breeds. Journal of Genetics and Genomics, 34(6), 510518. https://doi.org/10.1016/S1673-8527(07)60056-3

14. Lai, S.-J., Y.-P. Liu, Y.-X. Liu, X.-W. Li \& Y.-G. Yao. 2006. Genetic diversity and origin of Chinese cattle revealed by mtDNA D-loop sequence variation. Molecular Phylogenetics and Evolution, 38(1), 146154. https://doi.org/10.1016/j.ympev.2005.06.013

15. Loftus, R.T., O. Ertugrul, A.H. Barbar, M.A.A. ElBarody, D.E. Machugh, S.D.E. Park \& D.G. Bradley. 1999. A microsatellite survey of cattle from a centre of origin: The Near East. Molecular Ecology, 8(12), 2015-2022. https://doi.org/10.1046/j.1365294X.1999.00805.X

16. Loftus, R.T., D.E. MacHugh, D.G. Bradley, P.M. Sharp \& P. Cunningham. 1994. Evidence for two independent domestications of cattle. Proceedings of the National Academy of Sciences of the United States of America, 91(7), 2757-2761. https://doi.org/10.1073/ pnas.91.7.2757

17. Loftus, T. Ronan, D.E. MacHugh, D.G. Bradley, P.M. Sharp \& P. Cunningham. 1994. Evidence for two independent domestications of cattle. Proceedings of the National Academy of Sciences of the United States of America, 91(7), 2757-2761. https://doi.org/10.1073/ pnas.91.7.2757

18. Mannen, H., M. Kohno, Y. Nagata, S. Tsuji, D.G. Bradley, J.S. Yeo, D. Nyamsamba, Y. Zagdsuren, M. Yokohama, K. Nomura \& T. Amano. 2004. Independent mitochondrial origin and historical genetic differentiation in North-Eastern Asian cattle. Molecular Phylogenetics and Evolution, 32(2), 539544. https://doi.org/10.1016/j.ympev.2004.01.010

19. Mannen, H., S. Tsuji, R.T. Loftus, \& D.G. Bradley. 1998. Mitochondrial DNA variation and evolution of Japanese black cattle (Bos taurus). Genetics, 150(3), 1169-1175.

20. Neopane, S.P., \& P.K. Pokharel. 2005. Indigenous cattle of Nepal. Animal Breeding Division National Animal Science Research Institute (NASRI) and Nepal Agricultural Research Council (NARC).

21. Rana, R.B. 1996. Annual Report on Morphological characteristics and production performance of lulu cattle of Mustang District 1995/96. National Animal Science Research Institute.

22. Rozas, J., \& R. Rozas. 1999. DnaSP version 3: An integrated program for molecular population genetics and molecular evolution analysis. Bioinformatics, 15(2), 174-175. https://doi.org/10.1093/ bioinformatics/15.2.174

23. Sharma, R., A. Kishore, M. Mukesh, S. Ahlawat, A. Maitra, A.K. Pandey \& M.S. Tantia. 2015. Genetic diversity and relationship of Indian cattle inferred from microsatellite and mitochondrial DNA markers. $B M C$ Genetics, 16(1), 73. https://doi.org/10.1186/s12863015-0221-0

24. Sun, T., G. Huang, J. Sun, Z. Wang, S. Teng, Y. Cao, Q. Hanif, N. Chen, C. Lei \& Y. Liao. 2020. Mitogenome diversity and maternal origins of guangxi buffalo breeds. Animals, 10(4), 1-7. https://doi.org/10.3390/ ani10040547

25. Takeda, K., M. Satoh, S.P. Neopane, B.S. Kuwar, H.D. Joshi, N.P. Shrestha, H. Fujise, M. Tasai, T. Tagami \& H. Hanada. 2004. Mitochondrial DNA analysis of Nepalese domestic dwarf cattle Lulu*. Animal Science Journal, 75(2), 103-110. https://doi.org/10.1111/ j.1740-0929.2004.00163.x

26. Tamura, K., D. Peterson, N. Peterson, G. Stecher, M. Nei \& S. Kumar. 2011. MEGA5: Molecular Evolutionary Genetics Analysis Using Maximum Likelihood, Evolutionary Distance, and Maximum Parsimony Methods. Molecular Biology and Evolution, 28(10), 2731-2739. https://doi.org/10.1093/molbev/ msr121

27. Troy, C., D. MacHugh, J. Bailey, D. Magee, R. Loftus, P. Cunningham, A. Chamberlain, B. Sykesk \& D. Bradley. 2001. Genetic evidence for Near-Eastern origins of European cattle. Nature, 410, 1088-1091. https://doi.org/10.1038/35074088

28. Troy, C.S., D.E. MacHugh, J.F. Bailey, D.A. Magee, R.T Loftus, P. Cunningham, A.T. Chamberlain, B.C. Sykes \& D.G. Bradley. 2001. Genetic evidence for NearEastern origins of European cattle. Nature, 410(6832), 1088-1091. https://doi.org/10.1038/35074088

29. Yu, Y., L. Nie, Z.-Q. He, J.-K. Wen, C.-S. Jian \& Y.P. Zhang. 1999. Mitochondrial DNA variation in cattle of South China: Origin and introgression. Animal Genetics, 30(4), 245-250. https://doi.org/10.1046/ j.1365-2052.1999.00483.x 